\title{
Wheat compounds - A comprehensive review
}

\author{
Muhammad Hanif Mughal* \\ Homeopathic Clinic, Islamabad, Pakistan
}

\begin{abstract}
Wheat bran is recognized as one of the prominent and economically cheap sources of dietary fibers, minerals, vitamins, bioactive compounds and is also used to prepare many food-based commodities. Wheat is considered unique among all cereal crops because it has a special protein called gluten that is produced with the rheological features needed to make leavened bread during the process of dough production. Consumption of wheat bran improves the health and prevents some diseases including colon cancer, cardiovascular diseases. The current review article discusses the importance of wheat bran, its composition, extraction methods and its health benefits.
\end{abstract}

\section{Introduction}

Cereals are regarded throughout humanity as one of the world's most significant staple foods. Cereals have also been used in energy production in recent times, i.e. through fermentation processes resulting in biogas / bioethanol manufacturing. Among these cereals, oats, wheat, barley maize, rye, millet, and sorghum are well recognized. Nearly $60 \%$ of the world's cultivated soil is used for the cultivation of grasses. In general, five wheat species are grown around the globe, namely spelt wheat and prevalent hexaploid wheat, tetraploid durum wheat and emmer and diploid einkorn, whereas triticale is simply a man-made hybrid range of durum wheat and rye [1].

Grain type and nature determines the amount of bran fraction, bran generally accounts for almost 3 to $30 \%$ of dry grain weight. The bran portion's outer layer consists of pericarp \& testa (plant coat), while the internal layer consists of the aleurone neurons discovered very close to the endosperm part. Few cereal grains, including barley, oat \& rice, outer portion is tightly bound to outer portion of bran layer. Bran part is a wealthy source of micro-and macronutrients including flavonoids, fiber, minerals, vitamins, proteins, and minerals. Germ part accounts for almost 4 to 17 percent of whole grain's dry weight. This part is also a large source of different biomolecules such as lipids, vitamin B \& E and proteins. While endosperm fraction ranges from almost 65 to 75 percent of whole grain's dry weight, which is mostly consist of polysaccharides (starch, non-starch) and traces of lipoids and proteins [2].

Throughout commercial grain milling, bran and germ layers are manually separated to ensure the final quality of the product and to increase the shelf life of the resulting refined flour. Despite this, during the production of refined flour, different nutrients are lost. Flour produced through a milling process in which all the major components of cereal grain (bran, germ and endosperm) are retained in the resulting flour, known as whole grain flour [3]. Whole grain flour is known in a balanced proportion as it is found in cereal grain as a complete cache of all vital components. Full-grain diet was known to reduce the risk of various metabolic syndromes such as cancer, diabetes, cardiovascular disorders and obesity [4].

Bread's role in human nutrition is primarily due to three main reasons: first, high starch content; second, the presence of nearly all macro / micro-nutrients; and third, the availability of various flavoring substances. Breadstuffs, mostly whole meals and brown breads are considered to be more important components in our daily diet compared to white bread as they are a rich source of biomolecules that curtail the effects of various metabolic syndromes such as neoplastic and cardiovascular diseases [5,6]. In addition, Polish bread is increased with various flavor enhancing substances, fiber additives, multigrain bran and dried vegetables resulting in enhanced flavoring and nutritional profile of the finished product. In addition to this, durum wheat (Triticum durum) is sometimes used as a bread improver [7]. With regard to the nutritional aspects of white bread, it must be supplemented with various bioactive compounds to counteract nutrient loss due to the grinding process.

\section{Nutritional profiling}

Because of its health modulating viewpoint, the wheat germ is well known among nutritionist. Wheat germ has $10.80 \%$ water, $26.50 \%$ crude protein, $8.56 \%$ crude fat and $4.18 \%$ ash content on a dry weight basis $[8,9]$. Wheat germ contains lipids $(10 \%-15 \%)$, proteins $(26 \%$ $35 \%)$, sugars (17\%), fiber(1.5\%-4.5\%)and minerals (4\%), in addition to these it also contains substantial amount of biologically active compounds, for instance tocopherols, phytosterols, policosanols, carotenoids, thiamin and riboflavin as $300-740 \mathrm{mg} / \mathrm{kg}, 24-50 \mathrm{mg} / \mathrm{kg}$, $10 \mathrm{mg} / \mathrm{kg}, 4-18 \mathrm{mg} / \mathrm{kg}, 15-23 \mathrm{mg} / \mathrm{kg}$ and $6-10 \mathrm{mg} / \mathrm{kg}$, respectively. Raw wheat germ contains about $11 \%$ of moisture content, $31.40 \%$ of crude protein, $18.50 \%$ of dietary fiber and $7.0 \%$ of crude fat content. It also includes essential amino acids such as isoleucine $(4.06 \mathrm{~g} / 100 \mathrm{~g})$, leucine (10.47 g/100 g), lysine (10.26 g/100 g), methionine (2.08 g/100 $\mathrm{g})$, phenylalanine $(5.03 \mathrm{~g} / 100 \mathrm{~g})$, threonin $(2.54 \mathrm{~g} / 100 \mathrm{~g})$, tryptophan $(1.80 \mathrm{~g} / 100 \mathrm{~g})$ and valine $(6.21 \mathrm{~g} / 100 \mathrm{~g})[10,11]$.

Mineral deficiency is now one of the world's most pressing issues. About three billion people around the globe suffer from deficiencies in

*Correspondence to: Muhammad Hanif Mughal, Homeopathic Clinic, Islamabad, Pakistan, E-mail: drmhanifmughal@gmail.com

Key words: wheat, bran, polyphenols, cardiovascular role, diabetes

Received: September 21, 2019; Accepted: October 14, 2019; Published: October 17,2019 
minerals. Because of mineral deficiency, premature deaths, decreased labor productivity and high healthcare costs have risen. Minerals are considered to be essential nutrients that human beings need for proper human development in their daily diet. Minerals are categorized into two major groups, i.e. macro-minerals (potassium $(\mathrm{K})$, calcium $(\mathrm{Ca})$ and magnesium $(\mathrm{Mg})$, etc.) required in large quantities on a daily basis and micro-minerals (iron $(\mathrm{Fe})$, copper $(\mathrm{Cu})$, boron $(\mathrm{B})$, zinc $(\mathrm{Zn})$ and selenium (Se), etc.) also known as trace elements necessary in smaller quantities [12]. Different metabolic functions rely on minerals such as enzyme activation in the human body. Similar chronic diseases may be attributed to micronutrient deficiencies including vitamins and minerals. The highest content of crude ash (nearly $3 \%$ ) was documented in crisp bread, whereas the lowest (nearly $1 \%$ ) was found in wheat \& rye bread and amaranthus-mixed brown bread. The difference in calcium (Ca) concentration ranged from 6 to $10 \mathrm{mg} 100 \mathrm{~g}-1$ on fresh weight basis in all experimented bread types. While in pumpkin and crisp rice, calcium had a fresh weight base of 20.40 and $16.30 \mathrm{mg} 100 \mathrm{~g}-1$, respectively [13].

Starch is a polysaccharide that is formed from glucose molecule polymerization. Starch molecule consists of two amylose \& amylopectin polymer forms. Amylose is a linear structure with $a-(1,4)-a$ glycosidic relation of glucose molecules with DP (polymerization degree) ranging from 1000 to 5000 glucose units. Amylopectin is a branched structure consisting of 20 to 25 glucose units. The amylose-amylopectin ratio is almost constant, i.e. 23. Amylopectin is a molecule composed of $\alpha$-(1,4)-glycosidic glucose-connected molecules linked to 5 to 6 percent of $\alpha$-(1,6)-connected glucose molecules [14].

\section{Rheological role}

Instruments used to evaluate cereals ' rheological properties are regarded as critical means used by analytical laboratories to determine the characteristics of raw materials and end products. It helps to analyze manufacturing conditions, product quality forecasts and, most importantly, market acceptability. Rheology is defined as a science related to the pouring and twisting of a particular material. It is important to have information about the mechanical and rheological properties of different food systems in order to design the processes flow for quality control, texture design of the product and predict the response of the product under storage conditions [15].

Depending on the type and cultivar of a subjected wheat plant, the rheological properties differ. Few of these varieties are ideal for the production of bread. Every variety has certain specific ingredients with specific rheological features. Rheological properties of dough change at each step / stage during bread production. If dough is mixed in high speed mixer, it transforms into coherent and elastic mass owing to high stress conditions that prevail at particular high speed. Textural characteristics are directly related to rheological properties, including shelf-life stability, taste and mouth feeling [15].

Rheological characterization of bread quality dough is an authenticated element that tests the capacity of dough to contract and ensures the properties of dough handling. In practice, various methods such as extensograph, amylograph, farinograph and mixograph are used for flour rheology. Farinograph is used to carry out realistic rheological dough quantifications. Farinograph results provide knowledge of the quantity of water to be added in dough development, assess the requirements for flour mixing, and examine the consistency of flour [16].

Manu and Prasada-Rao studied the rheological properties of wheat flour. They found dough development time, water absorption capacity, and dough stability time as 2 minutes, 61.30 percent, and 8.25 minutes, correspondingly. The dough resistance was also estimated as 9 minutes. Farinograph was used to explore variations in Pakistani wheat varieties ' water absorption capacity. Butt, et al. tested three Pakistani varieties for their farinographic properties. Water absorption in Pakistani varieties ranged from 63.80 to 66.00 percent. We also defined dough softening, dough development time and stumpy dough consistency ranging from 10 to $105 \mathrm{BU}$, from 2.20 to 5.50 minutes, correspondingly among the examined Pakistani wheat varieties (Table 1) [17].

Amylograph is generally used to test cereal flour's pasting properties. In addition, $a$-amylase is an indigenous enzyme which breaks starch into simple sugars in wheat. Values from falling number test are crucial for determining the final product quality as there is a linear relationship among $\alpha$-amylase activity and various end product quality characteristics like load volume and bread crumb value. $a$-amylase activity (falling number $=250$ ) in flour is required for proper baking process to occur. In particular, the dropping number check value greater than 250 means that flour is perfect for the cycle of bread production. In contrast, high $a$-amylase activity produces dark loafcrust bread. Caramelization of sugar results in sticky and darkened crust of bread, which also causes problems during bread slicing [18].

\section{Immunochemical characteristics}

\section{Gluten}

Gluten is a wheat protein which consists primarily of gliadin and glutenin; it also includes lipids (3-7\%), minerals (0.50-0.90\%) and carbohydrates (7-16\%) in its structure. Gluten rheology tends to demonstrate the quality of wheat flour. Gluten-free wheat is rheologically classified as more viscous and less elastic than glutenfree [19]. Soft glutens undergo structural change (solid to liquid-like structure) with increasing frequency, whereas strong glutens up hold the elastic framework larger than soft glutens [20].

Wheat proteins have unique properties, but in nature they are complex. Different mechanical properties of wheat proteins affect the characteristics of dough making and baking. Type of protein also affects the quality of flour baking. Cereal wheat contains four different proteins, namely albumins, glutenins, globulins, and prolamins [21]. Proteomic analysis revealed that most of the endosperm portion of barley $\&$ wheat

Table 1. Bioactive compounds per $100 \mathrm{~g}$ of wheat

\begin{tabular}{|c|c|c|}
\hline Sr. No. & Bioactive components & Quantity/100 g of wheat bran \\
\hline 1 & Ferulic acid & $500-1500 \mathrm{mg}$ \\
\hline 2 & Alkylresorcinols & $220-400 \mathrm{mg}$ \\
\hline 3 & Iron & $11 \mathrm{mg}$ \\
\hline 4 & Manganese & $12 \mathrm{mg}$ \\
\hline 5 & Phytic acid & $2180-5220 \mathrm{mg}$ \\
\hline 6 & Lutein & $97-140 \mu \mathrm{g}$ \\
\hline 7 & Selenium & $78 \mu \mathrm{g}$ \\
\hline 8 & Vitamin E & $1.4 \mathrm{mg}$ \\
\hline 9 & Zinc & $7.3 \mathrm{mg}$ \\
\hline 10 & Choline & $47-100 \mathrm{mg}$ \\
\hline 11 & Betaine & $1000-1300 \mathrm{mg}$ \\
\hline 12 & Niacin & $14-18 \mathrm{mg}$ \\
\hline 13 & Panthothenic acid & $2.2-3.9 \mathrm{mg}$ \\
\hline 14 & Thiamin & $0.54 \mathrm{mg}$ \\
\hline 15 & Pyridoxin & $1-1.3 \mathrm{mg}$ \\
\hline 16 & Folate & $79-200 \mu \mathrm{g}$ \\
\hline 17 & Riboflavin & $0.39-0.75 \mathrm{mg}$ \\
\hline 18 & Biotin & $0.048 \mathrm{mg}$ \\
\hline
\end{tabular}


albumin belongs to the family of aamylase / trypsin inhibitors [22]. The portions of gliadin and glutenin are primarily proteins produced during the grain cycle [21].

Gliadins are soluble in aqueous alcohol and are a heterogeneous polypeptide mixture. These gliadins on fractionation through PAGE (electrophoresis of polyacrylamide gel) at low $\mathrm{pH}$ could be classified into three subgroups labeled as $\alpha, \beta$, $\pi$-gliadins. In intra-molecular di-sulfide bonding, these proteins are vital, making total stability. Therefore, in the production of bread using wheat flour these are considered to be less significant. Protein gliadin has strong extensibility, but lacks elasticity, which is a critical mechanical property in the production of dough [23]. Conversely, as opposed to gliadins, glutenins are multi-chain polypeptides of greater molecular weight. By fact, these are naturally elastic. The mixture of glutenin and gliadin results in dough extensibility and elasticity resulting in various baking products being used. Gluten's visco-elastic properties are significantly influenced by the gliadin-glutenin ratio. Our ratio could also be used to compare the quality of the baked product produced from different cultivars of wheat [24].

Wheat quality is investigated during the bread making cycle through the structure of wheat storage proteins that ultimately control protein interaction [21]. Protein content in wheat flour significantly changes the quality of bread making. The molecular weight of wheat flour proteins is primarily responsible for formed dough's visco-elastic properties. High molecular weight glutenin plays a vital role in the viscoelastic properties of dough in this sense [25]. Glutenin is one of the largest naturally occulting protein structures. Glutenin proteins are naturally heterogeneous formed by the polypeptide di-sulphide bond [26]. It was previously recorded by Triticum aestivum L's Lawrence and Payne [27] glutenin part. It accounts for almost $40 \%$ of the total protein grain. Glutenin fraction plays a vital role in deciding the elasticity and strength of the wheat flour dough. Because it contains the whole amount of higher molecular weight proteins formed from the relation between the number of polypeptide chains. Several scientists have tried to find out the exact structure of gluten protein, but they face difficulty doing so because of this form of protein's lack of crystallinity and low solubility. Gluten's solubility properties are characterized by its compositional protein structures and intermolecular interactions such as covalent di-sulphide bonding and non-covalent binding.

Gliadins are proteins that are made from a mixture of monomeric polypeptides, while glutenins consist of peptide polymers connected by di-sulphide bonds. Glutenin protein consists of mixed subunit polymers with low molecular weight glutenins and high molecular weight gluteinine subunits [28].

\section{Environment impact on proteins}

The quality of flour formed from cereal crops is usually significantly affected by environmental factors. Climate has effects on polymerization degree, amount of specific proteins, protein groups and subunits, relative structure, concentration, size and volume of polymeric proteins. Fertilizer, water distribution, and temperature are the most important environmental factors. The period for grain growth, final protein \& starch content and grain weight changes during grain filling time [29]. Protein performance in wheat grain is also determined by the networking of glutenin subunits within the protein structure that is affected by the wheat plant's cultivable environmental conditions. Due to increased levels of accumulated grain nitrogen content and decreased rates of accumulated carbohydrates, protein content in cereal meal is significantly elevated under water deficit conditions.
Similarly, irrigation can decrease protein content in meal by diluting nitrogen along with carbohydrates [30]. Wheat seed moisture content is negatively correlated with wheat processing protein polymerization.

Temperature plays a critical role in deciding the protein concentration in the grain filling cycle of spring wheats. The concentration of protein depends on cultivar variation, varying application of fertilizer, and seasonal fluctuations, according to an investigation. The proportion of gliadin to glutenin increases at elevated temperatures while the amount of larger polymers decreases [31].

Wheat endosperm contains $20-25 \%$ of total cereal grain proteins in globulins and albumins. It is understood that both proteins globulins and albumins have a strong amino acid balance from a nutritional point of view. Most of these cereal proteins are metabolic enzymes active in metabolic pathways on a daily basis. Although it is not well known the functionality of numerous other proteins. Few proteins are known for their defense mechanism especially belonging to trypsin and $\alpha$-amylase inhibitors family, on the other hand role of trypsin \& $a$-amylase inhibitors have also been characterized as allergens in baker's asthma. Additional biologically active proteins had a significant impact on wheat flour's rheological \& processing characteristics. The beneficial use of glucooxidase, amylases, pentosanases, xylanases and lipoxygenase enzymes have motivated researchers ' interest in exploiting them in the bread industry [32].

Wheat is considered unique among all cereal crops because it has a special protein called gluten that is produced during the process of dough production with the rheological characteristics needed to make leavened bread. Not only in the production of bread, but also in the production of other baked goods such as cookies, pasta, pocket breads and noodles, gluten rheological characteristics are needed [33].

Gluten proteins consist of gliadins and monomeric glutenins. Such proteins are known as the main storage proteins in traditional bread wheat, consisting of about 75 to 85 percent of the total cereal grain protein in ratio 1 and 1 . Perhaps high in proline, asparagine, glutamine, and arginine, but poor in amino acids such as methionine, lysine, and tryptophan [34].

\section{Therapeutic effect of wheat on human maladies}

Arabinoxylan; a fiber consisting of b-D-xylan backbone along with $\alpha-1,2$ \& $\alpha-1,3$ glycosidic connected side chains of arabinose. The value of wheat bran arabinoxylan ranges from 5-2639 grams/100 grams of wheat bran [35]. In practice, various methods are used to extract arabinoxylan, including enzymatic, mechanical and chemical methods of isolation. Hell, et al. [36] conducted an experiment to determine the best technique for extraction, including enzymatic, chemical and mechanical pretreatments for aranbinoxylan extraction. We claimed that mechanical extraction was the strongest of all in this extraction technique as mechanical effort was applied. Instead, the findings were significantly influenced by enzymatic and chemical extraction as various bioactive compounds other than arabinoxylan were also obtained with these techniques. It was noted that sifting after electrostatic isolation resulted in the highest dry weight content (43\%) of arabinoxylan [37].

Arabinoxylan (AX) has antioxidant potential, likely due to the covalent bonding of plant phenols with arabinoxylans. In a trial on fifty-five individuals in which the subjects in breakfast cereal are given an arabinoxylan at a varying dose of 2 to 5 grams for a threeweek duration. The results of this study showed substantial elevation in serum postprandial ferulic acid concentration and faecal bifido 
bacteria. It was also stated that $\mathrm{AX}$ reduces post-prandial glycemic response by preserving viscosity in the gut portion while minimizing the risk of type II diabetes as it was isolated from endosperm portion of AX of endosperm portion of wheat [38].

\section{Diabetes}

Diabetes Mellitus (DM) is publicly known as the most common chronic ailment around the world and is also documented as foremost reason for illness and death. According to American Diabetes Association (2010) nearly 347 million people in the whole world are suffering from diabetes mellitus [39]. It mainly has two types; type 1 $\& 2$. Type 1 is caused by impaired functionality of beta secretion cells in pancreas resulting in improper secretion of insulin hormone. Type II occurs due to reduced power in receptivity of peripheral insulin receptors located in peripheral tissues. People with diabetes typically have problems such as polyuria, hyperglycemia, polyphagia, glucosuria, and polydipsia [40]. Diabetes may cause irreversible tissue damage to various parts of the body resulting in cardiovascular diseases, retinopathy, arteriosclerosis and nephropathy due to prolonged exposure to hyperglycemic conditions [41].

Streptozotocin (STZ), a cytotoxic substance derived from soilbased microbes, is often used in experimental rodent models to cause diabetes. This cytotoxic material actually penetrates the cell structure of pancreatic beta-secreting cells by breaking the DNA strand of $\beta$-secreting cells, resulting in a drastic decrease in hormone insulin production resulting in serum glucose levels being altered in experimental subjects. Numerous explorations have shown that Streptozotocin's cytotoxic effects are primarily due to the release of Reactive Oxygen Species (ROS) and intracellular release of Nitric Oxide. This may also be attributed to the antioxidant \& oxidant content of excess serum and alkylation of DNA [42].

In another study, oral administration of germ oil $(300 \mathrm{mg} / \mathrm{kg} / \mathrm{b} . \mathrm{wt}$. and $500 \mathrm{mg} / \mathrm{kgb}$.wt.) to STZ-induced diabetic male Sprague Dawely rats and reduced contents of liver MDA, percentage of $\mathrm{HbAlc}$, atherogenic index and serum lipid profile while high density lipoproteins concentration was significantly elevated [43].

Research has shown that specific microbial enzymes can degrade gluten proteins. Research have shown that patients with $\mathrm{CD}$ have increased gliadin metabolizing enzymes of bacterial origin relative to healthy humans. It was also reported that $\mathrm{CD}$ can begin with proteolysis of gliadin by bacteria in the intestinal tract. This is mainly due to immunogenic gluten peptide formation. This probable involvement of gut microbiota in pathogenesis of $\mathrm{CD}$ is evidently supported by various studies ensuring compositional changes duodenal microflora of gut. Conversely, intragastric gluten administration to a rat model of $\mathrm{CD}$ (AVN rats) at the time of birth prompted gluten enteropathy topographies. On the other hand, intragastric application of gluten to AVN rats (an animal model of CD) at the time of birth induced gluten enteropathy characteristics [44]. The application of vancomycin and fusidic acid decreased the incidence of diabetes in a study on biobreeding rats (BBRs). Diabetes development may also be prevented by feeding heat to NOD mice killed by Lactobacillus casei. Diabetes incidence improves in germ-free mice relative to NOD mice born by SPF. This suggests the likely development mechanism of the innate immune system during disease onset. These findings suggest that commensal microflora has altered and prevented the effect of type-I diabetes. The intake of gluten protein significantly influences the composition of intestine microflora as NOD mice have been fed gluten- free diet having reduced gram-positive bacteria as compared to mice that were fed with a diet comprising of wheat proteins. According to a study by Marietta, et al. gluten protein enriched diet explicitly increases Bifidobacterium, Barnesiella and Tannerellaspecieswhile the concentration of Akkermansia species elevated in intestinal microflora of NOD mice fed on gluten free diet. Results from various animal modeling studies have revealed that prevalence of type-I diabetes is affected by both dietary patterns and intestinal microflora. When antidiabetic diets were first experimented in germ-free conditions, it was discovered that microflora independent mechanisms were the main reason for protectingproperties of subjected diets; on the other hand, hydrolyzed casein based diet showed microflora dependent antidiabetic effect. Patrick, et al. found that cereal-based diets were effective antidiabetic agents relative to gut microbes; thus, administering a hydrolyzed caseinbased diet was perceived as having a significant antidiabetic effect that could be accomplished by adjusting the microbiota.

In an initial human study, the titers of auto-antibody did not show momentous differences on gluten-free diet administration. Nevertheless, the findings of the insulin-tropic response glucose tolerance test improved in twelve out of fourteen patients who had gluten-free diets. Upon switching to normal diet, the critical response to insulin decreased in 10 out of 13 patients studied. In another study, a five-year-old boy with type-I diabetes without CD was performed. This patient was exposed to gluten-free diets, resulting in a reduction in $\mathrm{HbAl}$ c from $7.8 \%$ to $5.8-6.0 \%$ without hormonal insulin therapeutic application. Blood glucose is regulated at 4-5 mmol l-1 under fasting conditions. The boy was still without routine insulin treatment even after twenty months of diagnosis, suggesting that the gluten-free diet maintained remission in an experimented participant.

Earlier, it was found that the dosage or volume of gluten ingested was important to maintain a responsive immune response to gluten. At the same point as the gluten-free diet, NOD mice fed a diet four times higher than the standard diet showed safety from type 1 diabetes. This result is confirmed by studies that demonstrate dose-dependent effects of gluten on the development of type 1 diabetes in NOD mice, where high concentrations of wheat returned diabetes to the same degree as control mice.

Wheat germ oil in STZ induced diabetic rats inhibits LPO which occurs in plasma membrane and damages the membrane structure and permeability through scavenging lipid peroxyl radicals to yield lipid peroxides and the tocoperoxyl radicals and improving beta cells function. This oil not only decreased damage to serum glucose and glycated hemoglobin, plasma TC, TGs, LDL-C, MDA and oxidative nucleic acid, but also improved HDL-C and increased antioxidant enzyme superoxide dismutase. Lowering blood glucose levels and oxidative stress factors thus improve dyslipidemia and maintain the integrity of the vessel's wall. Wheat germ oil also contains polycosanol; a material that can help to lower levels of increased blood sugar and/ or cholesterol.

In addition, long-term injury, dysfunction and failure of various organs are associated with chronic hyperglycemia in DM. Liver is an insulin-dependent tissue that plays a bio-vital role in homeostasis of glucose and lipids and is severely affected by DM. In addition, $\beta$ cells of the Langerhans islets in the pancreas were damaged by STZ. The death of pancreatic $\beta$-cells in Langerhans islets and the loss of insulin secretion was caused by the immune-mediated identification of islet $\beta$-cells by auto-reactive T cells, accompanied by the release of pro-inflammatory cytokines and ROS. Cell death is the final stage of cell damage and may occur as a result of apoptosis or necrosis. Such evidence backed our histopathological observations of untreated diabetic rats in the 
liver and pancreas. However, our results showed that high WGO dose was successful in relieving DM-induced histopathological lesions. The primary marker for apoptosis is Caspase-3. Caspases are specific proteases of cysteine-aspartyl which play a key role in apoptosis. Caspase- 3 is one of the downstream effector caspases for apoptotic pathways. Several in vitro studies have suggested that apoptotic pathways based on caspase are necessary for apoptosis of $\beta$-cells.

\section{Conclusion}

Wheat bran has different nutraceutical roles with different compounds. This type of wheat can be used in different countries to prevent starvation and deadly diseases. To reach its maximum potential health benefits, the use of this wheat branch for different food and drug applications needs to be improved.

\section{References}

1. Pruckler M, Siebenhandl-Ehn S, Apprich S, Höltinger S, Haas C, et al. (2014) Wheat bran based biorefinery 1 : composition of wheat bran and strategies of functionalization. LWT-Food Science and Technology 56: 211-221.

2. Fardet A (2010) New hypotheses fort the health protective mechanisms of whole-grain cereals: what is beyond fibre? Nutr Res Rev 23: 65-134.

3. Franz M, Sampson L (2006) Challenges in developing a whole grain database: Definitions, methods and quantification. J Food Compos Anal 19: S38-S44.

4. Jacobs DR Jr, Marquart L, Slavin J, Kushi LH (1998) Whole-grain intake and cancer: an expanded review and meta-analysis. Nutr Cancer 30: 85-96. [Crossref]

5. Arvola A, Lähteenmäki L, Dean M, Vassallo M, Winkelmann M, et al. (2007) Consumers' beliefs about whole and refined grain products in the UK, Italy and Finland. J Cereal Sci 46: 197-206.

6. Kadan RS, Phillippy BQ (2007) Effects of yeast and bran on phytate degradation and minerals in rice bread. J Food Sci 72: C208-211. [Crossref]

7. Tańska M, Zadernowski R, Konopka I (2007) The quality of bread supplemented with dried carrot pomace. Pol J Natur Sci 22: 126-136.

8. Bilgicli N, Ibanoglu S (2007) Effect of wheat germ and wheat bran on the fermentation activity, phytic acid content and color of terhana, a wheat flour-yoghurt mixture. Journal of Food Engineering 78: 681-686.

9. Bilgicli N, Elgun A, Herken EN, Turker S, Ertas N, et al. (2006) Effect of wheat germ and wheat bran on the chemical, nutritional and sensory quality of tarhana, a fermented wheat flour-yoghurt product. Journal of Food Engineering 77: 680-686.

10. Arshad MU, Anjum FM, Zahoor T (2007) Nutritional assessment of cookies supplemented with defatted wheat germ. Food Chemistry 102: 123-128.

11. Zhu K, Zhou KH, Qian HF (2006) Protein extracted from defatted wheat germ: Nutritional and structural properties. Cereal Chemistry 83: 69-75.

12. Martinez-Ballesta MC, Dominguez-Perles R, Moreno DA, Muries B, Alcaraz-Lopez C, et al. (2009) Minerals in plant food: effect of agricultural practices and role in human health. A review. Agron Sustain Dev 30: 295-309.

13. Branca F, Ferrari M (2002) Impact of micronutrient deficiencies on growth: The stunting syndrome. Ann Nutr Metab 46: 8-17.

14. Konik-Rose Ch, Thistleton J, Chanvrier H, Tan I, Halley P, et al. (2001) Glutenin in relation to breadmaking functionality. Critical Reviews in Food Science and Nutrition 42: 179-208.

15. Gupta RB, Batey IL, MacRitchie F (1992) Relationships between protein composition and functional properties of wheat flours. Cereal Chemistry 69: 125-131.

16. Janssen AM, Vereijken JM, Vliet TV (1991) Rheological studies on gluten. In Bushuk W, Thachuk R (Eds.), Gluten Proteins pp: 180.

17. Fowler DB (2003) Crop nitrogen demand and grain protein concentration of spring and winter wheat. Agronomy Journal 95: 260-265.

18. Carbonero P, Salcedo G, Sánchez-Monge R, Garcia-Maroto F, Royo J, et al. (1993) A multigene family from cereals which encodes inhibitors of trypsin and heterologousamylases. In: Aviles FX, editor. Innovations of Proteases and Their Inhibitors. Walter de Gruyter; Berlin, Germany, pp: 333-348.
19. Khatkar BS, Bell AE, Schofield JD (1995) The dynamic rheological properties of glutens and gluten subfractions from wheats of good and poor bread-making quality. Journal of Cereal Science 22: 29-44.

20. Khatkar BS, Fido RJ, Tatham AS, Schofield JD (2002) Functional properties of wheat gliadins. I. Effects on mixing characteristics and bread making quality. Journal of Cereal Science 35: 299-306.

21. Shewry PR, Halford NG (2002) Cereal seed storage proteins: Structures, properties and role in grain utilization. Journal of Experimental Botany 53: 947-958.

22. Singh J, Blundell M, Tanner G, Skerritt JH (2001) Albumin and globulin proteins of wheat flour: Immunological and N-terminal sequence characterization. Journal of Cereal Science 34: 85-103.

23. Cheftel JC, Cug JL, Lorient D (1985) Amino acids, peptides, and proteins. In OR Fennema (Ed.), Food Chemistry, pp: 296-298.

24. Graveland A, Bosveld P, Lichtendonk WJ, Marseille JP, Moonen JHE, et al. (1985) A model for the molecular structure of the glutenins from wheat flour. Journal of Cereal Science 3: 1-16.

25. Branlard G, Dardevet M, Saccomano R, Lagoutte F, Gourdon J (2001) Genetic diversity of wheat storage proteins and bread wheat quality. Euphytica 119: 59-67.

26. Thompson S, Bishop DHL, Tatham AS, Shewry PR (1994) Exploring disulphide bond formation in a low molecular weight subunit of glutenin using a baculovius expression system. In: Gluten Proteins, pp: 345-355.

27. Lawrence GJ, Payne PI (1983) Detection by gel electrophoresis of oligomers formed by the association of high molecular weight glutenin protein subunits of wheat endosperm. Journal of Experimental Botany 34: 254-267.

28. Shewry PR, Tatham AS (1990) The prolamin storage proteins of cereal seeds: Structure and evolution. The Journal of Biochemistry 1: 1-12.

29. Dupont FM, Altenbach SB (2003) Molecular and biochemical impacts of environmental factors on wheat grain development and protein synthesis. Journal of Cereal Science 38: 133-146.

30. Ozturk A, Aydin F (2004) Effect of water stress at various growth stages on some quality characteristics of winter wheat. Journal of Agronomy and Crop Science 190: 93-99.

31. Johansson E, Prieto-Linde ML, Gissén C (2008) Influences of weather, cultivar and fertiliser rate on grain protein polymer accumulation in field-grown winter wheat, and relations to grain water content and falling number. Journal of the Science of Food and Agriculture 88: 2011-2018.

32. Merlino M, Leroy P, Chambon C, Branlard G (2009) Mapping and proteomic analysis of albumin and globulin proteins in hexaploid wheat kernels (Triticum aestivum L.). Theor Appl Genet 18: 1321-1337.

33. Uthayakumaran S, Newberry M, Phan-Tien N, Tanner R (2002) Small and large strain rheology of wheat gluten. Rheol Acta 41: 162-172.

34. Shewry PR (2007) Improving the protein content and composition of cereal grain. $J$ Cereal Sci 46: 239-250.

35. Fardet A (2010) New hypotheses for the health-protective mechanisms of whole-grain cereals: what is beyond fibre? Nutr Res Rev 23: 65-134. [Crossref]

36. Hell J, Donaldson L, Michlmayr H (2015) Effect of pretreatment on arabinoxylan distribution in wheat bran. Carbohydrate Polymers 121: 18-26.

37. Wang J, Smits E, Boom RM, Schutyser MAI (2015) Arabinoxylans concentrates from wheat bran by electrostatic separation. Journal of Food Engineering 155: 29-36.

38. Bernstein AM, Titgemeier B, Kirkpatrick K, Golubic M, Roizen MF (2013) Major cereal grain fibers and psyllium in relation to cardiovascular health. Nutrients 5: 14711487.

39. Danaei G, Finucane MM, Lu Y, Singh GM, Cowan MJ, et al. (2011) National, regional and global trends in fasting plasma glucose and diabetes prevalence since 1980: Systematic analysis of health examination surveys and epidemiological studies with 370 country-years and 2.7 million participants. Lancet 378: 31-40.

40. Poitout V (2008) Glucolipotoxicity of the pancreatic beta-cell: myth or reality? Biochem Soc Trans 36: 901-904. [Crossref]

41. Luitse MJA, Biessels GJ, Rutten GEHM, Kappelle LJ (2012) Diabetes, hyperglycaemia and acute ischaemic stroke. Lancet Neurol 11: 261-271.

42. Vikas K, Pankajkumar SY, Udayaa PS, Raj BH, Amar R, et al. (2011) Pharmacognostical evaluation of Cuscuta reflexa Roxb. Pharmacogn J 2: 74-82. 
43. Merghani BH, Awadin WF, Elseady YY, Abu-Heakal AN (2015) Protective role of wheat germ oil against hyperglycemia and hyperlipidemia in streptozotocin induced diabetic rats. Asian Journal of Animal and Veterinary Advances 10: 852-864.
44. Shrilatha B, Muralidhara M (2007) Early oxidative stress in testis and epididymal sperm in streptozotocin-induced diabetic mice: Its progression and genotoxic consequences. Reprod Toxicol 23: 578-587. [Crossref]

Copyright: (C2019 Mughal MH. This is an open-access article distributed under the terms of the Creative Commons Attribution License, which permits unrestricted use, distribution, and reproduction in any medium, provided the original author and source are credited. 